\title{
Dever's Model in Adolescent Pregnancy; An Epidemiological Review and Practice Recommendations for Health Care Providers
}

\author{
Michelle Ritter* \\ College of Nursing and Health Sciences, Valdosta State University, USA
}

*Corresponding author: Michelle Ritter, Associate Professor, Graduate Nursing Director, College of Nursing and Health Sciences, Valdosta State University, HSBA RM 4101, USA..

Received Date: February 26, 2020

Published Date: April 07, 2020

\begin{abstract}
Adolescent pregnancy rates in the United States (U.S.) have declined over the past few years. However, adolescent pregnancy remains an important public health issue in the U.S. Teen pregnancy continues to adversely affect the mom, infant, and community. Adolescent moms are more likely to engage in substance abuse, have lower socioeconomic status, and are more dependent on public assistance. Infants born to adolescent moms are more likely to suffer from health care issues such as low birth weight, neonatal death, and sudden infant death syndrome. Furthermore, adolescent pregnancy is estimated to cost US taxpayers 9 billion dollars each year. Despite the decline in the adolescent pregnancy rates, Healthy People 2020 identifies decreasing adolescent pregnancy as a priority in increasing the overall health and wellness of U.S. citizens. Epidemiologic studies can be used to identify adolescent pregnancy causal relationships, provide and understanding for these relationships, and recommend prevention options. Dever's model is used to analyze how adolescent pregnancy is influenced by human biology, life-style, environment, and the health care system. Health care providers serve as advocates for adolescent health and play an integral role in the reduction of adolescent pregnancy. However, in order to provide evidence-based and holistic patient care, providers should be knowledgeable with issues surrounding adolescent pregnancy.
\end{abstract}

\section{Introduction}

Over the past 10 years, adolescent pregnancy rates have declined among all racial and ethnic groups in the Unites States (U.S.). Between 2004 and 2014 adolescent pregnancy rates decreased $50 \%$ for adolescents $15-17$ years old, and 36\% for adolescents 18-19 years old [1]. In 2014, the overall adolescent birth rate declined to a historic low of 24.2 per 1,000 births [2]. Ethical disparities are still evident, with adolescent birth rates higher among Hispanics and African Americans. Adolescent birth rates for 15-19-year old's in 2014 were: 38.0 per 1,000 births for Hispanics. 35.9 per 1,000 births for African Americans; and 17.3 per 1,000 births for Caucasians [1]. Preliminary data for the adolescent birth rates for 2015 estimate yet another historic low. According the National Vital Statistics Report (2015) the adolescent birth rate for 15-19-year old's is down to 22.3 per 1,000 births. Even with the decline in the adolescent pregnancy rates, adolescent pregnancies still account for $11 \%$ of the U.S. annual births to mothers ages 10-19 [3]. Furthermore, the U.S. continues to rank first among developing countries in adolescent pregnancy (United Nations Statistics Division, 2015). Adolescent pregnancy continues to be an issue in the U.S. and has been defined as a public health and social concern in Healthy People 2020. Adolescent pregnancy can lead to adverse effects on the adolescent mom, the infant, and society. The purpose of this paper is to provide a brief overview of the impact adolescent pregnancy can have on the mother, offspring, and community; to use Dever's epidemiologic model to analyze adolescent pregnancy and how it is compacted by human biology, life-style, environment, and the health care system; and to discuss the role of health care providers in adolescent pregnancy. 


\section{Impact of Adolescent Pregnancy}

Pregnant adolescent females are more likely to abuse substances such as alcohol or tobacco during pregnancy and are more prone to psychosocial mood disorders [4-6]. They are less likely to complete high school or get married, tend to be of lower socioeconomic status, and are more dependent on public assistance [U.S. Department of Health and Human Services Healthy People 2020, (HP), 2016]. Pregnant adolescents are less likely to receive prenatal care, take prenatal multivitamins, and maintain adequate nutrition during pregnancy [7]. Furthermore, adolescent pregnancy is associated with medical complications for the adolescent mother such as poor maternal weight gain, anemia, pregnancy induced hypertension, and preeclampsia [4,7].

In addition to adverse health outcomes for adolescent mothers, children born to adolescent moms have increased health risks, and are more likely to experience social and emotional problems. Infants born to adolescent moms have an increased risk of unfavorable health outcomes such as perinatal mortality, pre-term birth and low birth weight, and are more prone to neonatal death $[8,7]$. The infant mortality rate is 1.6 times greater in adolescent mothers ages 15 and younger [7]. Sudden infant death syndrome (SIDS) is more common in infants born to teen moms [9]. These infants are also less likely to benefit from breast feeding [10]. Additionally, children of adolescent mothers are more likely to experience abuse and neglect, and less likely to receive adequate nutrition, health care, and cognitive and social $[10,11]$. Male offspring of adolescent mothers are $13 \%$ more likely to be incarcerated later in life, and $22 \%$ of female offspring of adolescent mothers are more likely to become adolescent mothers themselves (Schuyler Center for Analysis and Advocacy [SCAA], 2008). Adolescent pregnancy raises health care costs and burdens society. Teen pregnancy can be associated with financial repercussions due to lost tax revenue, increased public assistance costs, and increased expenditure in public health care. U.S. taxpayers incur an estimated 9 billion dollars per year due to adolescent pregnancy expenses [12]. In New York, taxpayer costs associated with adolescent pregnancy are estimated to account for $\$ 421$ million dollars of the state, federal and local funds (Schuyler Center for Analysis and Advocacy [SCAA], 2008).

\section{Dever's Model in Adolescent Pregnancy}

Dever's Epidemiologic model states a person's health status is influenced by a combination of different factors [13]. The concepts of Dever's model can be applied to adolescent pregnancy. Human biology, environmental factors, lifestyle factors, and health care system factors can contribute to risky adolescent sexual behaviors, which can consequently lead to pregnancy.

\section{Human biology}

Genetic inheritance, physiologic function, and maturation are subcategories of the Human Biology component in Dever's Epidemiologic Model that contribute to risky sexual behavior in adoles- cents. Genetic inheritance can play a role in teen pregnancy. African American and Hispanic adolescent females have the highest number of pregnancies among the different ethnic groups [1]. African American and Hispanic teens also report earlier age of coital initiation [14]. Puberty is a physiologic change occurring during adolescences which contributes to risky sexual behavior. The sudden influx of hormones may lead to increased sexual inclination and experimentation. Additionally, early onset of puberty in females has been linked to early sexual experimentation [15]. Maturation is another component of human biology in Dever's model, and an adolescent's maturation level also influences sexual behaviors. According to Erickson's developmental stages, adolescents are in the Identity versus Role Confusion stage [16]. They are very impressionable, and behavior is highly influenced by peers and media. Adolescents are cognitively immature and often do not connect a coital act with the consequence of pregnancy.

\section{Environmental factors}

Physical, psychological, and social environmental factors also contribute to risky sexual practices. A physical factor associated with sexual activity is the adolescents' home environment. Over 50 percent of children are raised in single parent households, leading to inadequate parental supervision and societal acceptance of single parenthood [17]. A lack of parental supervision and support increases the risk of sexual behavior [17]. Psychological factors such as low self-esteem and depression may also contribute to risky sexual practices [7]. Adolescent females with low self-esteem may seek unhealthy relationships and partake in unsafe sexual activity in order to increase their sense of self-worth. Recent research studies suggest a past history of childhood abuse has been linked with adolescent pregnancy [18]. Furthermore, social factors such as poverty and lower socioeconomic status are associated with adolescent pregnancy. African American and Hispanic females from lower socioeconomic status account for the higher rates of unplanned teen pregnancies. Data has shown the birth rate of poor adolescents $15-19$ years is 10 times greater than the birth rate of higher socioeconomic adolescents [14].

\section{Lifestyle factors}

Consistent with Dever's belief that lifestyle factors play the predominant role in determining a person's health risks, there are many lifestyle factors that contribute to risky sexual behaviors in teens. Frequency of sexual activity, early sexual debut, and nonuse or misuses of contraceptive methods are associated with adolescent pregnancy [19]. The average age of sexual debut for adolescent females is 17 years, with one fourth of adolescents reporting intercourse before the age of 15 [19]. According to Healthy People 2020, lack of or noncompliance with contraception is one of the main causes of unintended pregnancy in the United Sates. Substance abuse in teens has also been associated with unwanted pregnancy and an increase in sexually transmitted infections [U.S. Department of Health and Human Services Healthy People 2020, 
(HP), 2016]. Adolescent use of alcohol and drugs reduces inhibition and can influence sexual activity. Adolescent substance abuse had been associated with an increase in the number of sexual partners and with nonuse of contraception during intercourse [20]. Education assertiveness and involvement in pro-social activities are also lifestyle predictors of adolescent sexual behaviors. Teens engaged in afterschool activities and educational programs are less likely to become pregnant. Involvement in school clubs, athletics, and church positively contributes to adolescence deferral of sexual activity. In essence, sexual activity is decreased with greater involvement in school and academic activities [21]. Media influence is another predisposing factor of sexuality among teens. Adolescents spend an average of 3-4 hours per day watching television. Much of the media today is sexually suggestive. Mass media outlets shape teen portrayal of sexuality, and often provide misleading sexual information [22].

\section{Health care factors}

Health care factors play a role in the high rate of adolescent pregnancy. The specific health needs of adolescent care in the United States are understated. Factors include insufficient health coverage, lack of financial resources, lack of confidential resources, and inadequate transportation [23]. Additionally, there are limited health care specialists who focus on adolescent health. Adolescents rely on their parents for health coverage and transportation and may be uneasy confiding in them about sexuality issues. Although many states provide free contraception services to sexually active teens, they may not seek these services due to confidentiality. Teens wait an average of 9.5 to 14 months after the onset of sexual activity before seeking contraceptive health care, and majority of adolescent pregnancies occur in the first 6 months of sexual activity [19].

In summary, Dever's epidemiologic model can be used to identify intertwining factors impacting precarious adolescent sexual behaviors which can lead to adolescent pregnancy. Human biology factors of African American or Hispanic ethnicity, puberty, and immaturity; environmental factors such as lack of parental supervision, decreased adolescent self-esteem and/or depression, history of childhood abuse, and poverty or low-socioeconomic status; lifestyle factors including frequency of sexual activities, early age of sexual debut, incorrect or inappropriate use of contraception, substance abuse, medial influence, and lack of parental involvement and supervision; and health care system factors such as lack of financial resources, insufficient health care coverage, lack of confidential resources, lack of transportation, and limited adolescent health care specialist can lead to risky sexual behaviors in adolescents and inadvertently an adolescent pregnancy (Figure 1).

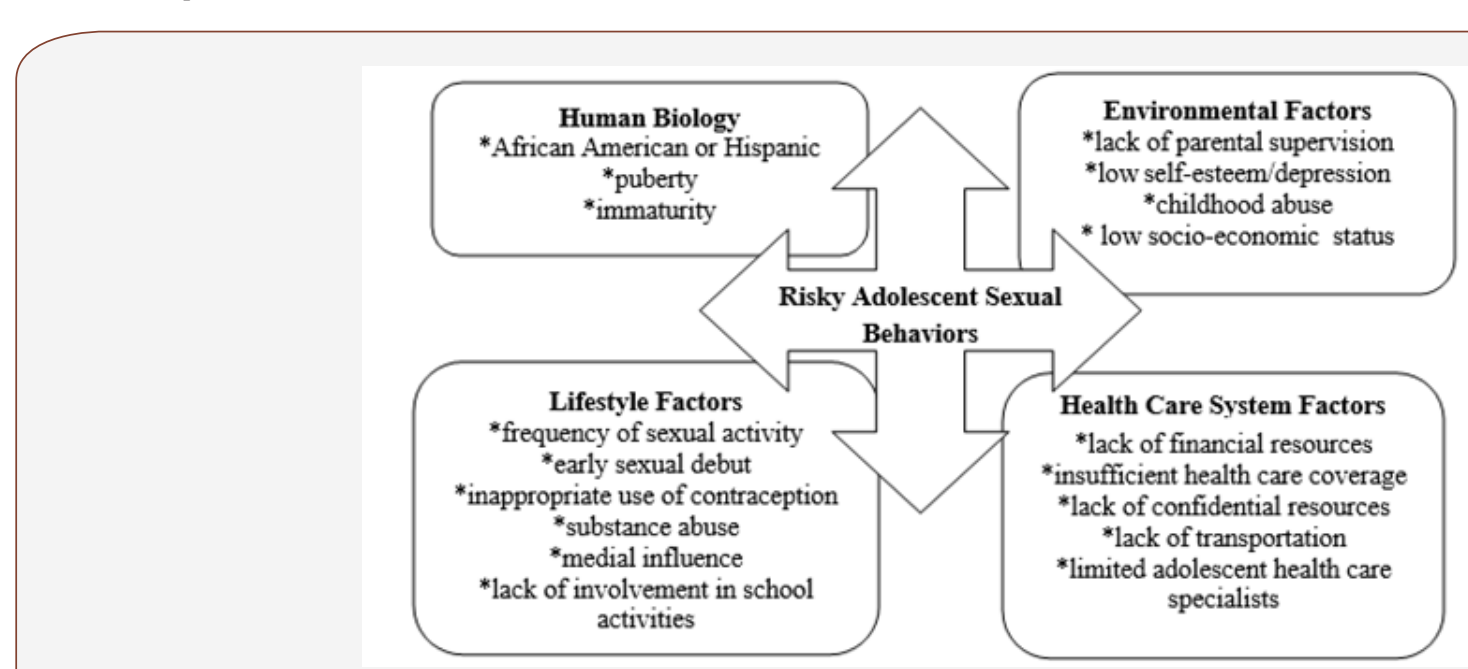

Figure 1: Dever's Model in Adolescent Pregnancy [1,7,14,15,17-23].

\section{Health care providers role}

Health care providers serve as advocates for adolescent health and play an integral role in the reduction of adolescent pregnancy. The provider's roles in health promotion for adolescent patients should include health care screenings, contraceptive counseling, and education. However, in order to provide evidence-based and holistic patient care, health care providers should be familiar with issues surrounding adolescent pregnancy. In addition to comprehending factors that may contribute to risky adolescent sexual behaviors, health care providers should also consider ethical and legal issues. Ethical and legal issues pertaining to adolescent pregnancy focus on the rights of adolescents to consent to healthcare services and to maintain confidentiality of these services. Sexually active teens are less likely to seek health care services if they must obtain parental consent [24]. Furthermore, an adolescent's ability to consent to family planning services, abortions, and prenatal care vary widely from state to state. However, certain situations allow adolescents younger than 18 to consent for health services without parental involvement. Examples of these situations include emergency care, emancipated minors, and state mandated situations. State mandated situations vary from state to state and include family planning services, abortions, and treatment of sexually transmitted 
infections (STI) [24]. To increase adolescent's accessibility to family planning services, the United States Supreme Court extended the constitutional right to privacy by allowing minors to obtain contraception without parental consent [24]. Each state has adopted different statutes on the age of consent for contraceptive services. Health care providers can access state specific information on adolescent consent for health care services from The Alan Guttmacher Institute at [24]. Adolescent's right to confidentiality also present legal and ethical concerns for the health care provider.

Research studies have found adolescents are less likely to seek family planning and STI services due to fear of parental notification [25]. The American Medical Association (AMA), American College of Nurse-Midwives (ACNM), Association of Women's Health Obstetric and Neonatal Nurses (AWHONN), and the American Academy of Pediatrics (AAP) all have position statements encouraging health care providers to maintain confidential adolescent family planning and STI services [24]. Pender's Health Belief Model states that successful health promotion activities vary according to the population served. In order for health promotion to be successful the populations' characteristics, behavior cognitions, and behavior outcomes must be addressed [26]. Race, education level, and socioeconomic status are all interconnected in establishing successful health promotion programs for adolescent females. To enhance change in health behaviors, the demographics of the population must be considered. Teenage pregnancy is more likely to occur in minority populations. Language barriers may prevent Hispanic adolescents from seeking health care and from receiving information on family planning services. Health care providers should be equipped with appropriate language pregnancy prevention educational resources for adolescent females. Attitudes about health care are also important in implementing successful health promotion programs. Teens have a lot of misconceptions related to sexual practices, and much of the information about sexual activity is solicited from media or friends [22]. Health care providers are in a position to educate adolescents on correct sexual practices information and debunk misconceptions. Additionally, health care providers should be knowledgeable on programs aimed at decreasing risky adolescent sexual behaviors. There are numerous programs in the US that address the urgency of adolescent pregnancy. Some programs are abstinence based, while others incorporate contraceptive education. However, the best programs aimed at reducing adolescent pregnancies are multi-factorial and encompass both abstinence and contraceptive education [27]. Examples of these programs include: Generations; AIM 4 Teen Moms; Love Notes; Positive Prevention PLUS; and Teen Options to Prevent Pregnancy (T.O.P.P.) (U.S. Department of Health and Human Service, 2016) [28,29]. Healthy People 2020 has been significant in establishing awareness on issues surrounding adolescent pregnancy in the U.S. Through its Family Planning initiative, HP 2020 notes the importance of reducing adolescent pregnancy to improve the overall health of society. The objectives in HP 2020 serve as a means for health care providers, governments, and com- munities to establish, implement, and measure programs that contribute to the overall health of the US population [30-32].

\section{Conclusion}

Although the adolescent pregnancy rates have decreased drastically over the last two decades, adolescent pregnancy remains a social and public health concern. Decreasing the rate of adolescent pregnancy in the U.S. remains multi-factorial. Dever's Model can be used to increase health care providers awareness of factors that can lead to risky adolescent sexual behaviors and consequently adolescent pregnancy. Health care providers serve as advocates for adolescent health. Routine health screens on adolescents should include inquiries on sexual activity and education on abstinence, condom use, contraception, and sexually transmitted infections. Providers should offer confidential services to sexually active teens and be knowledgeable on their state's statutes concerning adolescent health. Age of legal consent for health care services and confidentiality can affect the care of sexuality active adolescents. Health care providers should also serve as liaisons by educating teens with correct information on sexual practice. They can provide adolescent patients the guidance and tools needed to avoid unwanted pregnancy. Health care providers should collaborate and strengthen partnerships with health care agencies that influence family planning objectives. They can use the national Family Planning objectives in Healthy People 2020 as a guide to establish, implement, and evaluate best practice programs for the prevention of adolescent pregnancy. Health care providers must be aware of ongoing research pertaining to adolescent sexual behaviors and best evidence-based practices, to provide holist care to adolescents in their communities and aid in decreasing adolescent pregnancy.

\section{Acknowledgement}

None.

\section{Conflict of Interest}

No conflict of interest.

\section{References}

1. Hamilton BE, Martin JA, Osterman MJK, Curtin SC, Matthews TJ (2015) Births: final data for 2014. Natl Vital Stat Rep 64(12): 1-64.

2. Martin JA, Hamilton BE, Osterman MJ, Curtin SC, Matthews TJ (2015) Births: data for 2013. Natl Vital Stat Rep 64(1): 1-68.

3. Hamilton BE, Martin JA, Osterman MJ (2016) Preliminary data for 2015. Natl Vital Stat Rep 65(3): 1-14.

4. Beckman RB, Ling FW, Barzansky BM, Herbert WN, Laube DW, et al. (2010) Obstetrics and gynecology. ( $6^{\text {th }}$ edn), Lippincott Williams and Wilkins, Baltimore.

5. Birkeland R, Thompson JK, Phares V (2005) Adolescent motherhood and post-partum depression. J Clin Child Adolesc Psychol 34(2): 292-300.

6. (2010) U.S. Department of Health and Human Services. Office of Disease Prevention and Health Promotion. Healthy People.

7. Jorge L, Veronnie F (2012) Care of adolescent parents and their children. Pediatrics 130(6): 1743-1756. 
8. Brooks Gunn J, Furstenbergh FF (1986) The children of adolescent mothers: physical, academic and psychological outcomes. Developmental Review 6(3): 224-251.

9. Kost K, Landry DJ, Darroch JE (1998) The effects of pregnancy planning status on birth outcomes and infant care. Fam Plann Perspect 30(5): 223-230.

10. Dye TD, Wojtowycz MA, Aubry RH, Quade J, Kilburn H (1997) Unintended pregnancy and breast-feeding behavior. Am J Public Health 87(10): 1709-1711.

11. Deutscher B, Fewell R, Gross M (2006) Enhancing the interactions of teenage mothers and their at-risk children; effectiveness of a maternalfocused intervention. Topics in Early Childhood Education 26(1): 194205.

12. Magness J (2012) Adolescent pregnancy: the role of the health care provider. International Journal of Childbearing Education 27(4): 61-64.

13. Clark MJ (1999) Nursing in the Community. ( $3^{\text {rd }}$ edn), CT: Appleton Lange Community Guide (2010) Adolescent health home page, Stamford.

14. Santelli JS, Lowry R, Brener ND, Robin L (2000) The association of sexual behaviors with socioeconomic status, family structure, and race/ ethnicity among US adolescents. Am J Public Health 90(10): 1582-1587.

15. Downing J, Bellis MA (2009) Early pubertal onset and its relationship with sexual risk taking, substance use and anti-social behavior: a preliminary cross-sectional study. BMC Public Health 446(9): 12712458.

16. Dillon PM (2007) Nursing health assessment: A critical thinking, case studies approach. ( $\left.2^{\text {nd }} e d n\right)$, FA Davis, Philadelphia.

17. Arnold EM, Smith T, Harrison DF, Springer DW (2000) Adolescents' knowledge and belief about pregnancy: The impact of 'enable'. Adolescence 35(139): 485.

18. Francisco MA, Hicks K, Powell J, Styles K, Tabor JL, et al. (2008) The effect of childhood sexual abuse on adolescent pregnancy: an integrative research review. J Spec Pediatr Nurs 13(4): 237-248.

19. Klein DA, Adelman WP (2008) Adolescent pregnancy in the U.S. military: what we know and what we need to know. Mil Med 173(7): 658-665.
20. Zapata LB, Hillis SD, Marchbanks PA, Curtis KM, Lowry R (2008) Methamphetamine use is independently associated with recent risky sexual behaviors and adolescent pregnancy. J Sch Health 78(12): 641648.

21. Ramirez-Valles J, Zimmerman MA, Newcomb MD (1998) Sexual risk behavior among youth: modeling the influence of prosocial activities and socioeconomic factors. J Health Soc Behav 39(3): 237-253.

22. Pinkleton BE, Austin EW, Cohen M, Chen YC, Fitzgerald E (2008) Effects of a peer-led media literacy curriculum on adolescents' knowledge and attitudes towards sexual behavior and media portrayals of sex. Health Commun 23(5): 462-472.

23. Thomas A (2012) Policy Solutions for Preventing Unplanned Pregnancy. DC: Brookings, Washington.

24. Tillett J (2005) Adolescents and informed consent; ethical and legal issues. J Perinat Neonatal Nurs 19(2): 112-121.

25. Jones RK, Boonstra H (2004) Confidential reproductive health services for minors: the potential impact of mandated parental involvement for contraception. Perspect Sex Reprod Health 36(5): 182-191.

26. Pender NJ, Murdaugh CL, Parsons MA (2002) Health Promotion in Nursing Practice (edn), NJ: Prentice Hall, Upper Saddle River.

27. Gavin LE, Catalano RF, Markham CM (2010) Positive youth development as a strategy to promote adolescent sexual reproductive health. J Adolesc Health 46(3): 1-6.

28. (2016) An overview of minors' consent law. The Alan Guttmacher Institute.

29. Schuyler Center for Analysis and Advocacy [SCAA] (2008) Teen births: outcomes for young parents and their children.

30. United Nations Statistics Division (2015) Demographic Yearbook 2013. NY: United Nations, New York.

31. (2020) U.S. Department of Health and Human Resources Healthy People.

32. U.S. Department of Health and Human Resources (2016) Updated findings from the HHS teen pregnancy prevention evidence review. 